\title{
HISTOCHEMICAL AND IMMUNOHISTOCHEMICAL INVESTIGATION OF PELVIC SYMPHYSIS IN HOLSTEIN-FRIESIAN CATTLE
}

\author{
Piret Hussar ${ }^{1}$, Tõnu Järveots ${ }^{2}$, Mihkel Jalakas ${ }^{2}$ \\ ${ }^{1}$ Institute of Anatomy, University of Tartu, Tartu, Estonia \\ ${ }^{2}$ Institute of Veterinary Medicine and Animal Sciences, \\ Estonian University of Life Sciences, Tartu, Estonia
}

\begin{abstract}
Although the knowledges on morphological changes in cattle pelvic symphysis during gestation and obstetrics gives valuable information about the age of optimal primary calving of cows, up to now little research has been carried out about the ossification of pelvic symphysis. The aim of the study was to carry out histochemical and immunohistochemical comparative investigation of pelvic symphysis in calves, in-calfed and after-calved Estonian HolsteinFriesian's (EHF) cattle.

The material from the cranial part of the pubic bone, pubo-ischiadic junction, symphyseal eminence and the body of the interischiadic bone was taken for immunohistochemical investigation from eight EHF cows divided into three age groups: calves, in-calfed and after-calved EHF's. Specimen were fixed with $10 \%$ formalin, demineralized thereafter in EDTA and embedded into paraffin, slices $7 \mu \mathrm{m}$ in thickness were cut followed by histochemical staining by Safranin-O and immunohistochemical staining by primary antibodies Collagen-II and Periostin (Novus Biologicals, Littleton, CO, USA). Immunohistochemical staining was carried out according to the manufacturers quidleines (Invitrogen, Carlsbad, CA, USA).

Our investigations proved that the main morphological changes, the retardation of ossification processes, in the pelvic symphysis occur in adult EHF kines during the second-half of gestation in the pubo-ischiadic junction.
\end{abstract}

Keywords: Estonian Holstein-Friesian's cattle, pelvic symphysis, periostin, collagen-II 


\section{INTRODUCTION}

Up to now the structure and ossification processes of the cattle pelvic symphysis has been slightly studied. According to the literature in some species (e.g. guinea pigs, pocket gophers etc.), the osseous tissue of pelvic symphysis is resorbed and replaced by cartilage and connective tissue near birthing [1,2]. This phenomenon raises the question about the morphological changes near birthing in the cattle pelvic symphysis in that region. Our previous histological studies have shown the retardation of ossification in the pelvic symphysis of in-calved heifers [3]. The aim of the study was to carry out histochemical and immunohistochemical investigation of pelvic symphysis in in-calved Estonian Holstein-Friesian's (EHF) cattle comparatively with the investigations of pelvic symphysis in calves and after-calved EHF's cattle.

\section{MATERIAL AND METHODS}

The material from four different regions of cattle pelvic symphysis: the cranial part of the pubic bone, pubo-ischiadic junction, symphyseal eminence and the body of the interischiadic bone was taken for histochemical and immunohistochemical investigation from eight EHF cows divided into three age groups: calves (2), in-calved (4) and after-calved (2) EHF's. The age of in-calved and after-calved bovines was 3-7 years.

Specimens were fixed with $10 \%$ formalin, demineralized thereafter in EDTA and embedded into paraffin, slices $7 \mu \mathrm{m}$ in thickness were cut followed by histochemical staining by Safranin-O and immunohistochemical staining. In the sections for immunohistochemical staining endogenous peroxidase activity was blocked with $3 \% \mathrm{H} 2 \mathrm{O} 2$ and the sections were stained using Histostain-Plus Kit (Invitrogen, Carlsbad, CA, USA) according to the manufacturer's guidelines. Collagen-II and Periostin served as primary antibodies (Novus Biologicals, Littleton, CO, USA). The biotinylated secondary antibody and the streptavidin-conjugated peroxidase were used for the detection using DAB as chromogen giving brown coloration in positively stained cells and tissues. Samples were analyzed with Zeiss Axioplan 2 (Germany) light microscope. 


\section{RESULTS}

The cranial part of pubic bone consisted of hyaline cartilage in all groups; the chondral ossification type with the columns of chondrocytes was noted (Figure 1).

In the pubo-ischiadic junction of in-calved cattle with gestation of 4-5 months as well as in after-calved cattle group the osseous tissue and the hyaline cartilage were noted. In in-calved cattle with gestation of 7,5 months similarly to calves fibrous and elastic cartilage and dense connective tissue prevailed. Periostin was detected in the connective tissue islets lining between fibrous and hyaline cartilage in calves and in in-calved cattle with gestation of 7.5 months (Figure 2).

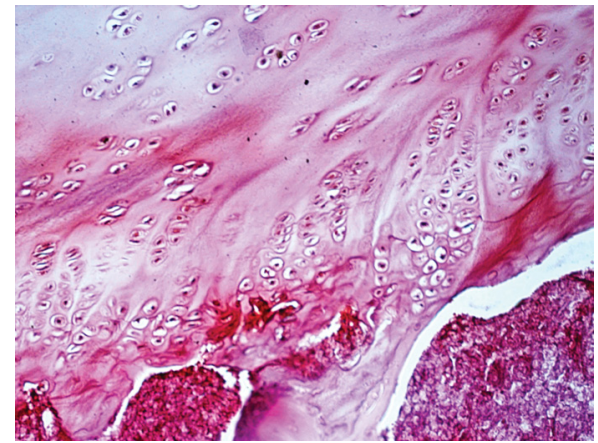

Figure 1. Hyaline-type cartilage in the cranial part of the pubic bone in aftercalved bovine. Safranin-O staining. Obj. 200x.

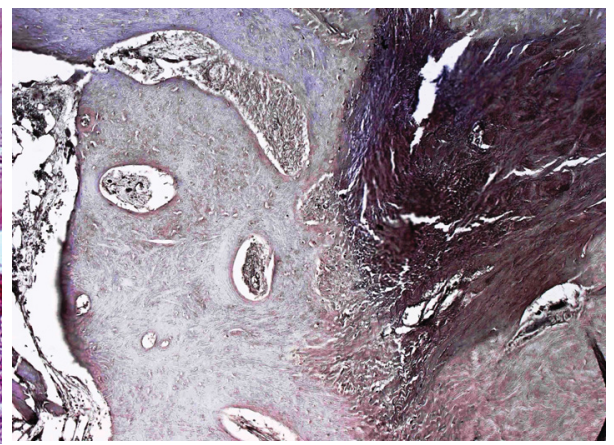

Figure 2. Periostin detected in the dense connective tissue in the pubo-ischiadic junction of in-calved cattle with the gestation of 7,5 months. Obj. 100x.

In the same group collagen-II was detected mainly in the chondrocyte nuclei of the hyaline cartilage (Figure 3).

In the symphyseal eminence of calves the dense connective tissue and cartilage prevailed. Immunohistochemically periostin was detected in the dense connective tissue (Figure 4). In other age groups a lot of osseous tissue was present.

The region of interischiadic bone of calves connective tissue proper and fibrous cartilage were noted; in in-calved and after-calved EHF's in the region the hyaline type of cartilage and osseous tissue prevailed (Figure 5). 


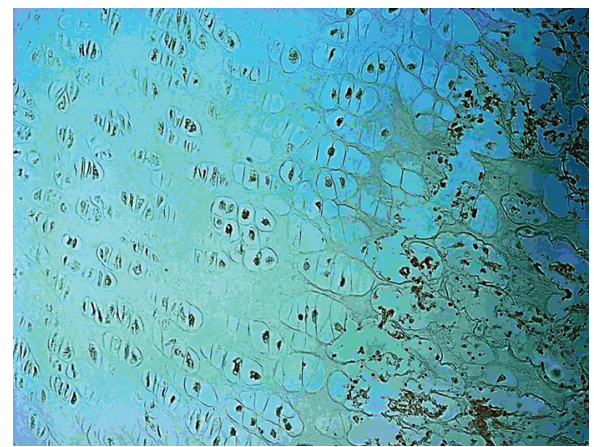

Figure 3. Immunohistochemistry for collagen-II. Collagen-II detected mainly in chondrocyte nuclei of the hyaline cartilage in the pubo-ischiadic junction of calves. Obj. 100x.

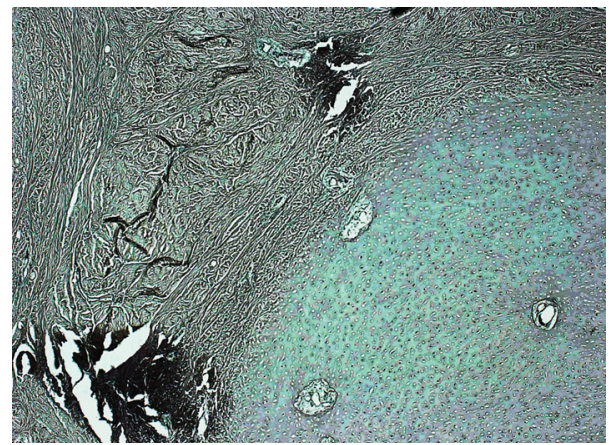

Figure 4. Immunohistochemistry for periostin. Periostin in cell-islets of dense connective tissue in the symphyseal eminence of calves. Obj. 50x.

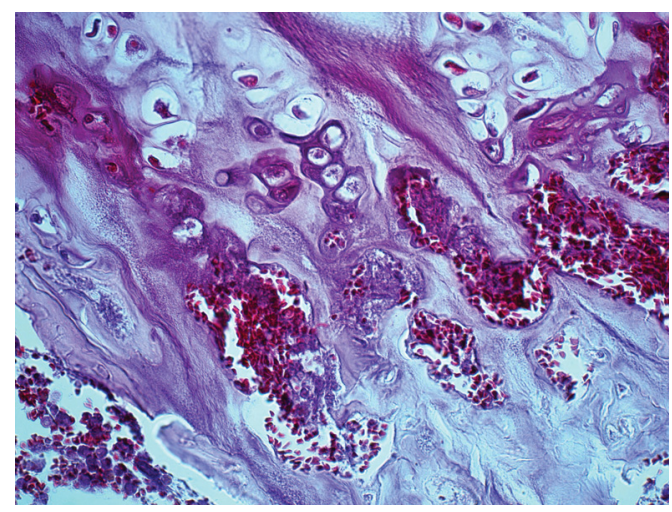

Figure 5. Hyaline-type cartilage in the region of interischiadic bone in bovine with 7.5 months gestation. Safranin-O staining. Obj. 400x.

\section{DISCUSSION}

Although the morphological changes in the pelvic symphysis in some small mammals (guinea pigs, mice, moles, pocket gopher, etc.) in the final stage of gestation have been well investigated, there is a lack of knowledges about these kinds of changes in bigger mammals, including cattle. The studies have proved that before birthing ligaments of the symphysis pubis stretch considerablely, which is presumably related to the changes in the tissues of symphyses during this period; after birthing the pubic and ischiadic bone join once again tightly $[1,2,4]$.

The partial resorption of the medial end of symphysis pubis during puberty has been observed in the experiments on mice [5]. It has been noted that precisely female sex hormons may also cause a separation of pubic bones [6-10]. Despite the wealth of morphological information about the extracellular matrix in this joint, little is known regarding to the involvement of the crimp 
of collagen fibers in the dramatic transformations occurring in this region during the last 3 days of pregnancy. Previous findings suggest that a disruption of the helical arrangement of the collagen containing fibers may contribute to explaining the rapid remodeling that occurs at the end of pregnancy and that is responsible for an increase in the pliancy and the length of the pubic ligament in mice [12]. There are also notes in literature about the role of proteoglycans and hyaluronic acid playing an important role in the remodeling of the extracellular matrix in these tissues during pregnancy [13].

The records of literature about the tissue changes during gestation and birthing in the pelvic symphyses of various mammalians led to our hypothesis about the changes in the ossification processes of bovine pelvic symphysis in that time period.

For the immunohistochemical study of EHF's cattle pubic symhysis antibodies against Collagen-II and Periostin were used. Collagen-II was used for the differentiation of the regions of chondrous and osseous tissues as the protein Collagen-II is the marker of differentiation and calcification existing in the chondrous tissue and being absent in the osseous tissue [14]. To refine the ossification types antibody against periostin was used. Periostin is mainly expressed by mesenchymal cells (fewer by chondrocytes) which have been regarded as the marker of intramembranous ossification [15].

According to our previous routine-histological studies, the main histological differences occurred in the region of pubo-ischiadic juction $[3,16]$. In cows with the gestation of $4-5$ months as well as in after-calved cows a lots of hyaline cartilage osseous tissue occurred in the pubo-ischiadic junction while in calves and in the cows in their final phase of gestation dense connective tissue and cartilage prevailed. The same type of morphological changes were also found by our present immunohistochemical studies when the cellislets of dense connective tissue in the pubo-ischiadic junction of calves and in in-calved cattle with the gestation of 7,5 months were noted by the periostin stain. It is known that the ossification of symphysis pubis is among the last ossification processes of the bones of pelvic symphysis of mammals. This data is supported by our previous and present studies showing that the symphysial eminence and the body of the interischiadic bone of cows in their first-half of gestation and in the after-calved bovines consists mainly of osseous tissue, while the cranial part of the pubic bone consists of hyaline cartilage. Previous studies have shown that the symphyseal eminence and the body of the interischiadic bone of the calves consists of connective tissue and cartilage [16-18]. In our experiments a lot of fibrous type of cartilage in the region of the interischiadic bone and the additionaly hyaline cartilage in the symphyseal eminence was noted. 


\section{CONCLUSIONS}

The histochemical and immunohistochemical study proved that the main histological changes in the pelvic symphysis of adult EHF kines occur during the second-half of gestation in the pubo-ischiadic junction. In after-calved as well as in in-calved cattle during their first-half of gestation the osseous tissue is prevailing meanwhile in calves and in cows with their second-half of gestation fibrous cartilage and the tight connective tissue is noted in this region.

The presence of periostin in the cell-islets of the dense connective tissue in the pubo-ischiadic junction of calves and in calved cattle with the gestation of 7.5 months as well as in the symphyseal eminence of calves may indicate to the intramembranous ossification in these regions.

Futher histochemical and immunohistochemical investigations are required to elaborate in more details the tissue changes in the pelvic symphysis in different age groups.

\section{ACKNOWLEDGEMENTS}

We wish to thank Mrs. Mare Tamm for her kind laboratory assistance.

\section{REFERENCES}

1. Duncan J.M. (1854). The behaviour of the pelvic articulations in the mechanism of parturition. Dublin Quarterly Journal of Medical Science, 18 (1), 60-69.

2. Hisaw F.L. (1924). The absorption of the pubic symphysis of the pocket gopher, Geomys bursarius. The American Naturalist, 58 (654), 93-96.

3. Hussar P., Padari M., Jalakas M., Järveots T. (2014). Histological Investigation of Pelvic Symphysis in Holstein-Friesian Cattle. Journal of Agricultural Science and Technology A, 4, 260-265.

4. Consonni S.R., Werneck C.C., Sobreira D.R., Kühne F., Moraes S.G., Alvares L.E., et al. (2012). Elastic fiber assembly in the adult mouse pubic symphysis during pregnancy and postpartum. Biol. Reprod., 86 (5), 151.

5. Gardner W.U. (1936). Sexual dimorphism of the pelvis of the mouse, the effect of estrogenic hormones upon the pelvis and upon the development of scrotal hernias. American Journal of Anatomy, 59, 459-483.

6. Kliman B., Salhanick H.A. (1952). Relaxation of pubic symphysis of the mouse during the estrous cycle and pseudopregnancy. Proc. Soc. Exp. Biol. Med., 81, 201-202.

7. Crelin E.S., Levin J. (1955). The prepuberal pubic symphysis and uterus in the mouse: Their response to estrogen and relaxin. Endocrinology, 57 (6), 730-747.

8. Crelin E.S. (1963). The development and hormonal response of the autotransplanted interpubic joint in mice. Anat. 146 (2), 149-163. 
9. Tague R.G. (1988). Bone resorption of the pubis and preauricular area in humans and nonhuman mammals. American Journal of Physical Anthropology, 76 (2),251-267.

10. Uesugi Y., Sato T., Iguchi T. (1993). Morphometric analysis of the pelvis in mice treated neonatally with tamoxifen. Anat. Rec., 235 (1), 126-130.

11. Pinheiroa M. C., Moraesa S. G., Battlehnerb C. N., Caldinib E. G., Toledoc O. M. S., JoazeiroP. P. (2004). Histochemical and ultrastructural study of collagen fibers in mouse pubic symphysis during late pregnancy, Micron., 35(8), 685-93.

12. Pinheiroa M.C. , Morab O.A., Caldinic E.G., Battlehnerc C.N., Joazeirod P.P., Toledo O.M.S. (2005). Ultrastructural, immunohistochemical and biochemical analysis of glycosaminoglycans and proteoglycans in the mouse pubic symphysis during pregnancy, Cell Biol Int., 29(6), 458-71.

13. Garcia E.A., Veridiano A.M., Martins J. R.M., Nader H.B.,Pinheiro M.C., Joazeiro P.P., Toledo O.M.S. (2008). Hyaluronan involvement in the changes of mouse interpubic tissue during late pregnancy and post-partum, Microsc Res Tech., 71(3),169-78.

14. Lane J.M., Suda M., von der Mark K., Timpl R. (1986). Immunofluorescent localization of structural collagen types in endochondral fracture repair. J. Orthop. Res., 4(3), 318-29.

15. Horiuchi K., Amizuka N., Takeshita S., Takamatsu H., Katsuura M., Ozawa H., Toyama Y., Bonewald L.F., Kudo A. (1999). Identification and characterization of a novel protein, periostin, with restricted expression to periosteum and periodontal ligament and increased expression by transforming growth factor beta. J. Bone Miner. Res., 14(7),1239-49.

16. Hussar P., Padari M., Järveots T., Jalakas M. (2010). Histology of cattle pelvis. In: Proceedings of the Conference "Healthy Animal and Healthy Food", Tartu, Estonia, pp. 20-22. (in Estonian).

17. Jalakas M., Saks P., Järv E. (2002). Apophysal ossification of the coxal bone of ehf cows and the interischial bone. In: Veterinaarmeditsiin, pp. 5-15.

18. Nahkur E., Jalakas M., Andrianov V., Ernits E., Järv E. (2003). Pelvis of the elk and cow-comparative morphology. Agraarteadus, 16 (3), 179-185.

\section{Address for correspondence:}

Assoc. Prof. Piret Hussar, M.D., D.M.Sc

Chair of Histology and Embryology

Institute of Anatomy, Faculty of Medicine

University of Tartu, Ravila 19, Tartu 50411, Estonia

E-mail: piret.hussar@ut.ee 